\title{
Synergistic effect of carbon nanotubes, copper and silver nanoparticles as an efficient electrochemical sensor for the trace recognition of amlodipine besylate drug
}

\author{
Gowhar A. Naikoo · Umar J. Pandit ${ }^{2}$. Mehraj U. D. Sheikh ${ }^{2}$. Israr UI Hassan ${ }^{3}$ Gulzar A. Khan ${ }^{2}$. Ajmal R. Bhat ${ }^{4}$. \\ Ratnesh Das ${ }^{2} \cdot$ Ridha Horchani ${ }^{5}$
}

Received: 6 March 2020 / Accepted: 22 April 2020 / Published online: 28 April 2020

(c) Springer Nature Switzerland AG 2020

\begin{abstract}
The electrochemically functionalized multiwalled carbon nanotubes/copper nanoparticles (fMWCNT/CuNPs) carbon paste electrode (fMWCNT/CuNPs-CPE) was successfully modified by silver nanoparticles (AgNPs) via electrocatalytic process. The formation of modified electrode (AgNPs/fMWCNT/Cu NP-CPE) was observed by Field Emission Scanning Electron Microscopy and X-ray diffraction techniques. The as-prepared electrodes were explored for the trace recognition of calcium channel blocker drug amlodipine besylate (ADB) using cyclic voltammetry and electrochemical impedance spectroscopy measurements. Kinetic parameters like electron transfer coefficient $(a)$, charge due to adsorption $\left(Q_{a d s}\right)$, surface coverage $(\Gamma)$, charge transfer coefficient $\left(R_{c t}\right)$, and apparent electron-transfer rate constant $\left(k_{a p p}\right)$ for the designed electrodes were evaluated. The nanoparticles based electrochemical sensor displayed high sensitivity, good selectivity and favorable catalytic ability for the oxidation of amlodipine besylate. The fabricated electrodes showed good reproducibility and stability towards the determination of anti-hypertensive drug ADB.
\end{abstract}

Keywords Electrochemical sensor · Functionalized carbon nanotubes . Amlodipine besylate

\begin{tabular}{|c|c|c|c|}
\hline \multicolumn{2}{|l|}{ Abbreviations } & \multirow[t]{2}{*}{ EIS } & \multirow[t]{2}{*}{$\begin{array}{l}\text { Electrochemical impedance } \\
\text { spectroscopy }\end{array}$} \\
\hline Ag NPs & Silver nanoparticles & & \\
\hline fMWCNT/Cu NPs & Functionalized multiwalled carbon & AdSWV & Adsorptive square wave voltammetry \\
\hline & nanotubes/copper nanoparticles & LOD & Limit of detection \\
\hline CPE & Carbon paste electrode & LOQ & Limit of quantification \\
\hline CV & Cyclic voltammetry & & \\
\hline MWCNTs & Multiwalled carbon nanotubes & & \\
\hline ADB & Amlodipine besylate & \multirow{2}{*}{\multicolumn{2}{|c|}{1 Introduction }} \\
\hline BR & Britton-Robinson & & \\
\hline FESEM & $\begin{array}{l}\text { Field Emission Scanning Electron } \\
\text { Microscope }\end{array}$ & \multirow{2}{*}{\multicolumn{2}{|c|}{$\begin{array}{l}\text { The development of highly efficient electrochemical sen- } \\
\text { sors using nanostructures of metal and metal oxides has } \\
\text { attracted the researchers for the qualitative and quanti- } \\
\text { tative analysis of organic molecules including pharma- } \\
\text { ceutical drugs and related molecules in biological and }\end{array}$}} \\
\hline SWAdV & $\begin{array}{l}\text { Square wave adsorptive stripping } \\
\text { voltammetry }\end{array}$ & & \\
\hline
\end{tabular}

Gowhar A. Naikoo, gahmed@du.edu.om; naikgowhar@gmail.com; Umar J. Pandit, umarche@gmail.com|'Department of Mathematics and Sciences, College of Arts and Applied Sciences, Dhofar University, Salalah, Sultanate of Oman. ${ }^{2}$ Department of Chemistry, Dr. Harisingh Gour University, Sagar, M.P., India. ${ }^{3}$ College of Engineering, Dhofar University, Salalah, Sultanate of Oman. ${ }^{4}$ Department of Chemistry, Govt; Degree College, Bijbehara, Jammu and Kashmir, India. ${ }^{5}$ College of Science, Sultan Qaboos University, Muscat, Sultanate of Oman. 
environmental concern [1]. In addition researchers have explored conducting polymers with metal and metal oxide nanoparticles and carbon nanotubes to enhance the sensitivity, stability and reproducibility of electrochemical sensors [2]. Indeed, the employment of gold $\mathrm{Au}$ ) and platinum (pt) based electrochemical sensors have shown incredible results. However, there application on commercial bases is restricted due to the limited reserves and high costs associated with them [2]. So, the selectivity of effective electrode modifiers has become a big challenge for the modern surface science technology [1]. To overcome the these issues, researchers have successfully explored alternative options such as ca-doped $\mathrm{ZnO}$ materials [1], nanosilica modified sensors [2], amberlite XAD-4 modified electrodes [3], Ruthenium doped $\mathrm{TiO}_{\mathrm{TO}} /$ reduced graphene oxide [4], nanoclay-based electrochemical sensors [5], coreshell nanostructure modified electrodes [6], maghemite nanocrystals decorated multi-wall carbon nanotubes [7], $\mathrm{ZnO} / \mathrm{G}$ nano composite modified carbon paste electrodes [8], silver doped $\mathrm{TiO}_{2} / \mathrm{CNTs}$ [9], Pt-Ni bimetallic nanoparticles [10] and platinum-cobalt and platinum-nickel bimetallic nanoparticles [11] for the qualitative and quantitative analysis of antihistamine, anti-inflammatory drugs along with for the biological and environmental matters.

Designing an electrochemical sensor for the promising potential applications is a debonair task however, the vital issues to take into consideration for fabricating such sensors includes minimal cost, low toxicity, easy renewable surface and the potential for real time monitoring $[12,13]$. Herein, we attempt to design, fabricate and characterize fMWCNT/CuNP-CPE decorated with AgNPs. As Ag and Cu are non-toxic, readily available and possess appreciable electrochemical and photocatalytic properties [14]. Nanoparticles supported on MWCNTs provide extra roughness to the conductive sensing interface and improved the electrocatalytic performance and conductive properties $[15,16]$. The designed electrode was further subjected to investigate an anti-hypertensive ADB drug. ADB has the highest oral bioavailability and longest half-life of elimination among several dihydropyridine derivatives [17]. Several analytical procedures have been reported for the determination of ADB in blood plasma and pharmaceutical preparations [18-22].

\section{Experimental}

\subsection{Chemicals and reagents}

Multiwalled carbon nanotubes (MWCNT) with outer diameter 5-20 nm, inner diameter of 2-10 nm, tube length of about $5-20 \mu \mathrm{m}$ and purity $>95 \mathrm{wt} \%, \mathrm{Cu}\left(\mathrm{NO}_{3}\right)_{2} \cdot 3 \mathrm{H}_{2} \mathrm{O}$, $\mathrm{AgNO}_{3}$ and $\mathrm{ADB}$ (purity $\geq 98 \%$ ) were purchased from
Sigma, India. All other chemicals and reagents were used of analytical grade (Merck, India). All solutions and reagents were prepared in doubly distilled water. A stock solution of ADB $4 \mathrm{mM}$ was prepared by dissolving $0.142 \mathrm{mg}$ $A D B$ in $10 \mathrm{~mL}$ ethanol. Standard solutions of ADB were prepared by diluting appropriate volumes of stock solution with ethanol and supporting electrolyte. A $0.05 \mathrm{M}$ Britton-Robinson (BR) buffer with $p \mathrm{H}$ 5.6-12.0 was used as supporting electrolyte. The $p \mathrm{H}$ adjustments were carried out by $0.01 \mathrm{M} \mathrm{NaOH}$.

\subsection{Instrumentation}

A NOVA software controllable Metrohm Autolab B.V. PGSTAT128N electrochemical workstation equipped with a three electrode assembly was employed for electrodeposition and electrochemical measurements. Systronics $\mu \mathrm{pH}$ 361 Digital Analyzer was used for maintaining the $\mathrm{pH}$ of all solutions. Frontline sonicater and Remi $8 C$ Laboratory Centrifuge were used for the preparation of $\mathrm{AMWCNT/Cu}$ nanohybrids and to affect complete dissolution of solutions. The morphological characterization of modified electrode surfaces was performed by using NOVA NANOSEM 450 FESEM and Bruker D-8 X-ray diffractometer using Cu-Ka radiations.

\subsection{Fabrication of electrochemical sensor}

\subsubsection{Synthesis of functionalized MWCNT/Cu hybrids}

The chemical functionalization of MWCNTs were carried out by dissolving in the mixture of concentrated $\mathrm{H}_{2} \mathrm{SO}_{4}$ and $\mathrm{HNO}_{3}(3: 1, \mathrm{v} / \mathrm{v})$, and sonicating it for $5 \mathrm{~h}$. The oxidative acid treatment of MWCNTs using acid mixture such as $\mathrm{H}_{2} \mathrm{SO}_{4} / \mathrm{HNO}_{3}$ [23-27] is used for the successful functionalization of $-\mathrm{COOH}$ on the opening end of the MWCNTs. During the treatment, a strong interaction between the oxidizing acid molecules and CNTs results in creation of defect sites on the graphite lattice. Consequently, these defect sites involves the replacement of one carbon atom from the CNT lattice with one or two more oxygen's to form functional groups such as carboxylic acid $(-\mathrm{COOH})$ on the CNT surface [28] and results in the functionalization of $-\mathrm{COOH}$ on the opening end of the CNTs. The resulting fMWCNTs were separated by centrifugation at $8000 \mathrm{rpm}$ and washed with double distilled water till $\mathrm{pH}$ of MWCNTs became neutral, finally dried in oven at $120^{\circ} \mathrm{C} .10 \mathrm{mg}$ of these functionalized MWCNTs were dispersed in an ultrasonic bath for about $8 \mathrm{~min}$ and then stirred on a magnetic stirrer with drop wise addition of $0.01 \mathrm{M} \mathrm{Cu}\left(\mathrm{NO}_{3}\right)_{2}$ solution at room temperature. The stirring was continued for $20 \mathrm{~h}$ followed by separation of solid fMWCNT/Cu nanohybrids 
by centrifugation at $5000 \mathrm{rpm}$. The solid product was dried under IR lamp to completely evaporate the solvent [29].

\subsubsection{Preparation of $f M W C N T / C u$ hybrid carbon paste electrode}

$21.5 \mathrm{mg}$ paraffin oil, $8.5 \mathrm{mg}$ fMWCNT/Cu hybrid and $10.5 \mathrm{mg}$ carbon powder was taken and manually homogenized to form a paste. The paste was filled in $2 \mathrm{~mm}$ polyethylene syringes pre-inserted $\mathrm{Cu}$ wire for external electric contact. Smoothening of electrode surface was accomplished by mechanically pressing the paste from the top and rubbing against a smooth and clean weighing paper. The electrode was designed as $\mathrm{MMWCNT/Cu} \mathrm{NP-CPE.} \mathrm{Bare}$ carbon paste electrode was prepared by mixing $13.6 \mathrm{mg}$ paraffin oil and $6.4 \mathrm{mg}$ carbon powder and similar procedure was followed for its fabrication and regeneration of smoothed surface. The fabricated electrodes were electrochemically activated by applying ten cyclic potential sweeps from $-1.0 \times 10^{3} \mathrm{mV}$ to $+2.010^{3} \mathrm{mV}$ in $0.1 \mathrm{M}$ nitric acid solution at the scan rate of $50 \mathrm{mVs}^{-1}$.

\subsubsection{Electrode surface modifications with silver nanoparticles}

The electrodeposition of nanoparticle film over the surface of electrode is an electrocatalytic process and the growth, purity, shape and thickness of nanofilm over electrode surface depends on concentration of analyte, number of cyclic sweeps and scan rate. The surface of fabricated fMWCNT/Cu NP-CPE was modified with Ag NPs by potentiodynamic deposition of Ag NPs. The effect of Ag NPs deposition was analyzed for test solution. The best peak response in terms of peak current intensities was observed with scan rate of $25 \mathrm{mVs}^{-1}$ for 15 cycles in the potential range of $-1.0 \times 10^{3} \mathrm{mV}$ to $+1.0 \times 10^{3} \mathrm{mV}$. The electrode was immersed in a solution of $10 \mathrm{mM} \mathrm{AgNO}_{3}$ containing $10 \mathrm{mM}$ $\mathrm{KNO}_{3}$. The solution was stirred for $10 \mathrm{~min}$ at room temperature, eventually, Ag NPs film was developed over the electrode surface by performing 15 consecutive cyclic potential sweeps at a scan rate of $25 \mathrm{mVs}^{-1}$ in the given potential range. This electrode was designed as Ag NP/fMWCNT/Cu
NP-CPE and thoroughly washed with distilled water and dried at room temperature. For comparison of studies $\mathrm{Ag}$ NP/fMWCNT-CPE was also fabricated via same procedure. The description of electrode surface modification with silver nanoparticles (Ag NPs) is shown in Scheme 1.

\subsection{Pharmaceutical sample preparation}

In all voltammetric studies exactly ten locally purchased Amlodac 5 and Amlopin tablets (containing $5 \mathrm{mg}$ Amlodipine) were manually grounded to homogenized powder in a mortar pestle. An accurately weighed $(0.071 \mathrm{mg}$ of this powder was dissolved in appropriate volume of solvent and supporting electrolyte to prepare stock solutions of pharmaceutical sample. The solution was sonicated for $20 \mathrm{~min}$ to affect complete dissolution and stored for further assay. Working solutions were prepared by transferring suitable aliquots of the stock solution and diluting with BR buffer and supporting electrolyte.

\subsection{Blood and urine sample}

Human blood (for serum and plasma sample preparation) and urine samples were collected from a healthy volunteer after obtaining there formal consents. The blood samples were centrifuged at $5000 \mathrm{rpm}$ for $30 \mathrm{~min}$ at room temperature to separate serum and plasma within $1 \mathrm{~h}$ of collection and kept frozen until analysis. The separated biological samples were deproteinized by adding $2 \mathrm{~mL}$ of acetonitrile. After vortexing for $30 \mathrm{~s}$, samples were centrifuged at $5000 \mathrm{rpm}$ for $15 \mathrm{~min}$ to eliminate protein residues. The supernatant was decanted and diluted with BR buffer $(\mathrm{pH}$ 10.2).

\subsection{Voltammetric procedures}

The required volume of the stock solution of standard and pharmaceutical sample of ADB was placed in a $50 \mathrm{~mL}$ beaker. The total volume was made to $25 \mathrm{~mL}$ with appropriate quantities of BR buffer ( $\mathrm{pH} 10.2$ ) and solvent. Square wave adsorptive stripping voltammetry (SWAdV) was employed for determining ADB. The optimized parameters
Scheme 1 Electrode surface modification with silver nanoparticles (Ag NPs)

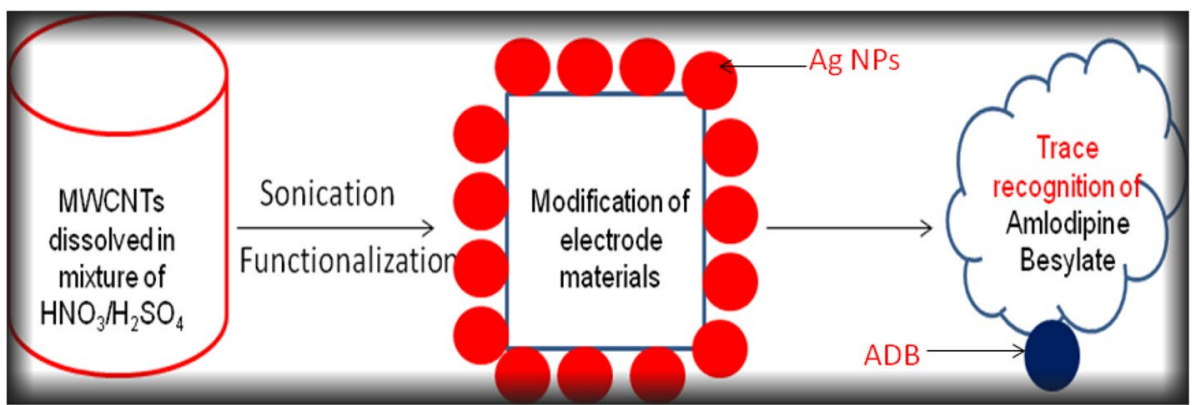

SN Applied Sciences A SPRINGER NATURE journal 
were: accumulation potential: $5.0 \mathrm{mV}$, accumulation time: $90 \mathrm{~s}$, equilibrium time: $10 \mathrm{~s}$, square wave frequency: $50 \mathrm{~Hz}$, step potential: $5 \mathrm{mV}$, modulation amplitude: $50 \mathrm{mV}$. Voltammograms were recorded in anodic direction from $0.0 \mathrm{mV}$ to $+8.0 \times 10^{2} \mathrm{mV}$. EIS study was performed at open circuit potential in the frequency range $10^{-1}-10^{6} \mathrm{~Hz}$.

\section{Results}

\subsection{Spectral and morphological characterization}

X-ray diffraction analysis of MWCNT, $\mathrm{MMWCNT/Cu}$ hybrid and Ag NP-fMWCNT/Cu indicate the formation of nanoparticles film on $\mathrm{AMWCNT}$-CPE surface (Fig. 1). The analysis was carried out in diffraction angle ranging from $2 \theta=10^{\circ}-90^{\circ}$, using Cu-Ka radiation ( $\lambda=1.5401 \AA$ ). The XRD patterns of fMWCNT shows the diffusive diffraction peaks appearing as small noises at $2 \theta$ values of $29.15^{\circ}, 44.80^{\circ}$ and $52.25^{\circ}$ corresponding to $d$-spacing and lattice planes of $3.06 \AA$ [002], $2.02 \AA$ [111] and $1.75 \AA$ [200] respectively [30]. After formation of $f M W C N T / C u$ hybrid, the XRD patterns obtained with diffraction peak at $2 \theta$ values of $28.51^{\circ}, 35.0^{\circ}, 43.03^{\circ}$, $62.01^{\circ}, 72.51^{\circ}$ and $77.88^{\circ}$ indexed to $d$-spacing and lattice planes at $3.12 \AA$ [110], $2.56 \AA$ [111], $2.08 \AA$ [200], $1.48 \AA$ [220], $1.30 \AA$ [311] and $1.22 \AA$ [222] respectively. However, the electrodeposition of Ag NPs film on fMWCNT/ $\mathrm{Cu}$ hybrid, the diffractions pattern of both $\mathrm{Cu}$ and $\mathrm{Ag}$ are distinctly observed (JCPDS file no. 04.783). The presence of these peaks confirmed occurrence of metallic $\mathrm{Cu}$ and Ag on the surface of $f M W C N T$.

The morphological and topographical visualization of surface of $f M W C N T-C P E, f M W C N T / C u$ NP-CPE, AgNPfMWCNT-CPE and Ag NP/fMWCNT/CU NP-CPE were

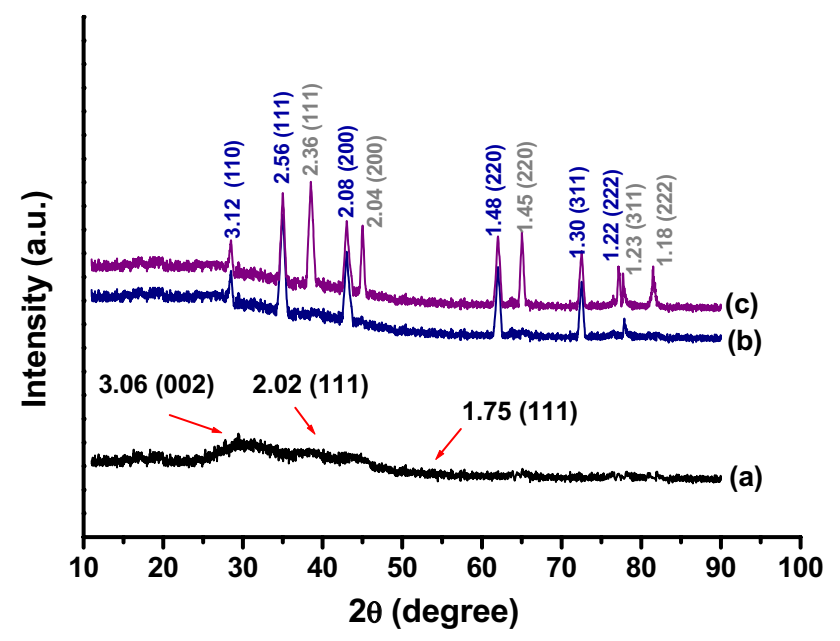

Fig. 1 XRD patterns of (a) MWCNTs, (b) MWCNT/Cu NPs and (c) Ag NP/MWCNT/Cu NPs performed by FESEM and has given a solid confirmation of presence of $\mathrm{Cu}$ and $\mathrm{Ag}$ NPs on the surface of MWCNTs. The FESEM monograph of $f M W C N T-C P E$ shown in Fig. 2a clearly shows dispersion of $f M W C N T s$ over the surface of carbon paste. The $\mathrm{fMWCNTS}$ are homogenously spread without agglomeration and looking twisted, bent and tangled. The formation of $\mathrm{MMWCNT/Cu}$ hybrid was clearly observed in FESEM monographs (Fig. 2b) while the electrodeposition of Ag NPs over fMWCNTs is visible in Fig. 2c. However, after the electrodeposition of Ag NPs over fMWCNT/Cu hybrid surface agglomerates which are almost regular and homogeneously dispersed over the surface (Fig. 2d).

\subsection{Cyclic voltammetric characterization of electrode}

The surface feature of bare and modified CPEs were characterized by $\mathrm{CV}$ employing $1.0 \mathrm{mM} \mathrm{K}_{3} \mathrm{Fe}(\mathrm{CN})_{6}$ probe in $0.1 \mathrm{M} \mathrm{KCl}$ solution. The quasi-reversible one electron redox behavior of $\mathrm{Fe}(\mathrm{CN})_{6}^{3-/ 4-}$ ions were observed on the bare CPE with $\triangle \mathrm{E}_{\mathrm{p}}$ (anodic and cathodic peak separation) of $3.62 \times 10^{2} \mathrm{mV}$ at scan rate of $50 \mathrm{mVs}^{-1}$. However, after the modification of CPE with FMWCNT, Cu NPs and Ag NPs, a decrease in $\Delta E_{p}$ was observed with increase in peak current. The surface areas of the electrodes were obtained by performing cyclic voltammetric measurements of the probe at different scan rates and employing Randles-Sevick equation [31]:

$I_{p a}=0.4463\left(\frac{F^{3}}{R T}\right)^{1 / 2} n^{3 / 2} A_{0} D_{0}^{1 / 2} C v^{1 / 2}$

where $I_{p a}$ is anodic peak current, $n$ is the number of electrons transferred, $A_{0}$ is surface area of the electrode $\left(\mathrm{cm}^{2}\right), D_{0}$ is diffusion coefficient, $C$ is concentration of $\mathrm{Fe}(\mathrm{CN})_{6}{ }^{3-/ 4-}$ and $v$ is the scan rate, $\mathrm{R}$ is molar gas constant (8.314 $\left.\mathrm{JK}^{-1} \mathrm{~mol}^{-1}\right)$ and $\mathrm{F}$ is Faraday's constant $(96,480 \mathrm{C}$ $\mathrm{mol}^{-1}$ ). For $1.0 \mathrm{mM} \mathrm{K}_{3} \mathrm{Fe}(\mathrm{CN})_{6}$ in $0.1 \mathrm{M} \mathrm{KCl}$ at $\mathrm{T}=298 \mathrm{~K}, \mathrm{n}=1$ and $D_{0}=7.6 \times 10^{-6} \mathrm{~cm}^{2} \mathrm{~s}^{-1}$. The surface area is calculated from the slope obtained from plot of $I_{p a}$ versus $v^{1 / 2}$. In the present work, the surface area of the b-CPE was calculated to be $0.052 \mathrm{~cm}^{2}$ and the microscopic surface area for fMWCNT-CPE, fMWCNT/Cu NP-CPE, Ag NP/FMWCNT-CPE and AgNP/fMWCNT/Cu NP-CPE was found as $0.272 \mathrm{~cm}^{2}$, $0.521 \mathrm{~cm}^{2}, 0.636 \mathrm{~cm}^{2}$ and $0.965 \mathrm{~cm}^{2}$ respectively.

\subsection{Electrochemical impedance spectroscopic (EIS) characterization of electrode}

EIS is performed to investigate the surface characteristics surface modified electrode material as an ultra-capacitor and to elucidate the differences among the electrochemical performance of bare and modified CPEs. The Nyquist 
Fig. 2 FESEM micrographs of a MWCNT, b MWCNT/Cu NP, c Ag NP/MWCNT and d Ag NP/ MWCNT/Cu NP
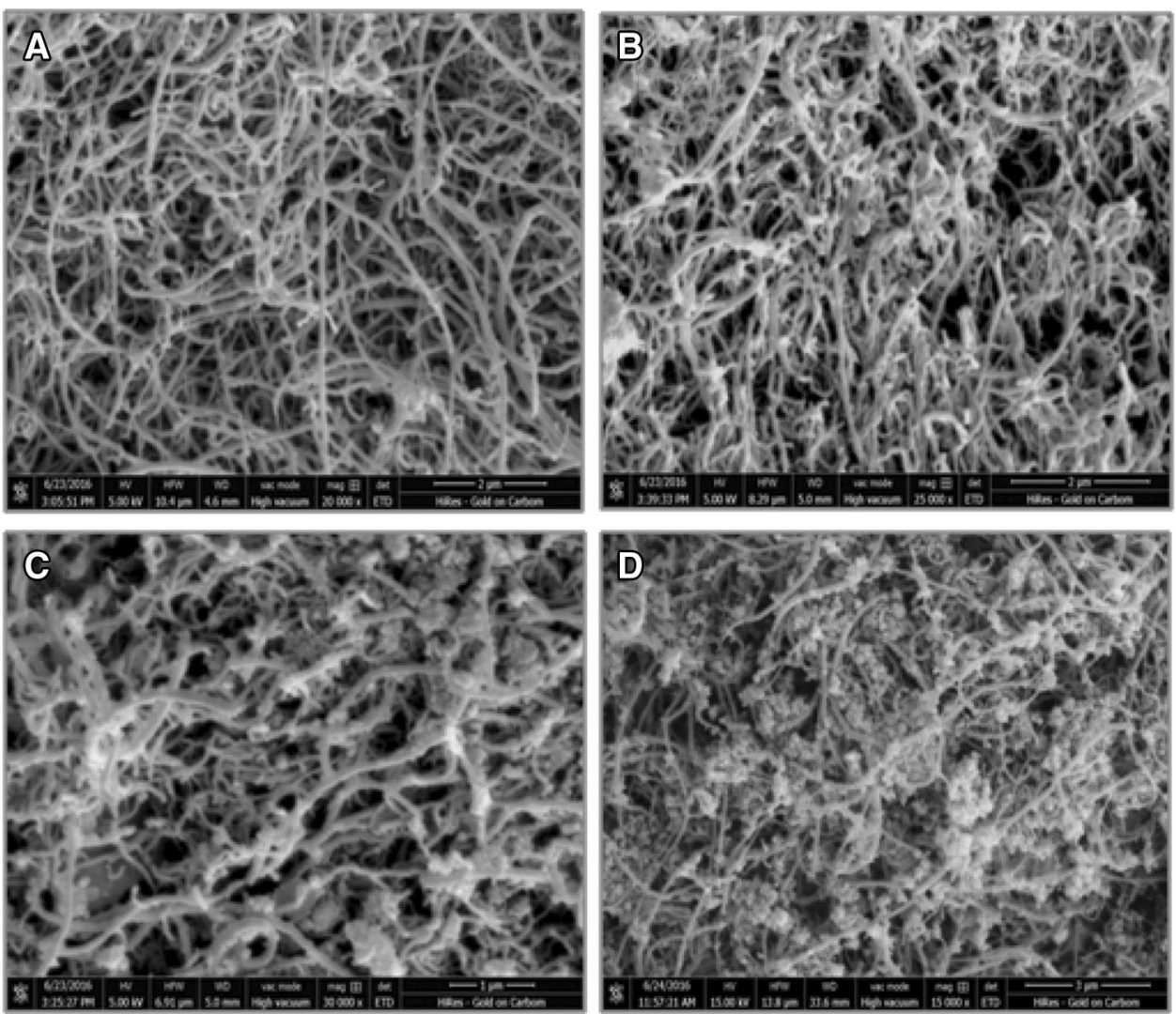

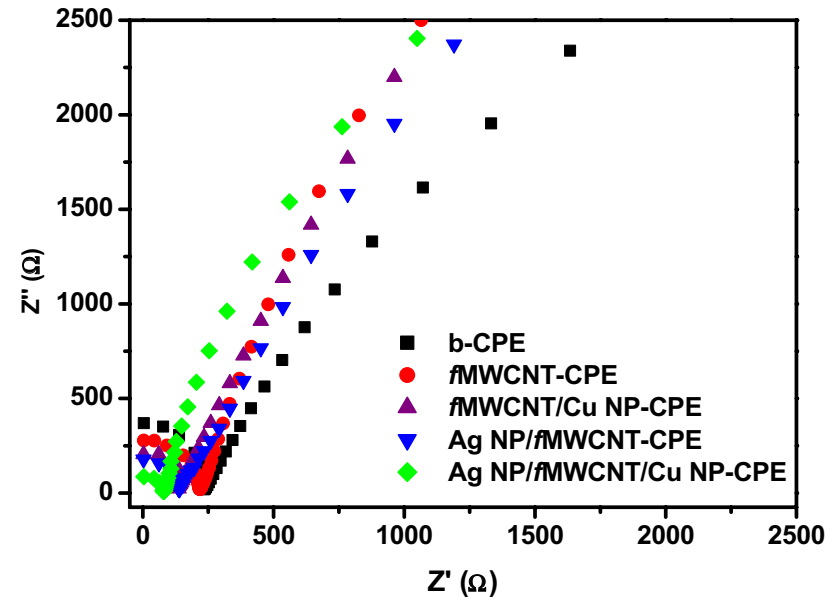

Fig. 3 Nyquist plot of $1.0 \mathrm{mM} \mathrm{Fe}(\mathrm{CN})_{6}{ }^{3-/ 4-}$ in $0.1 \mathrm{M} \mathrm{KCl}$ at different electrodes

plot for $1.0 \mathrm{mM} \mathrm{Fe}(\mathrm{CN})_{6}^{3-/ 4-}$ in $0.1 \mathrm{M} \mathrm{KCl}$ showed a significant difference in responses of electrodes as shown in Fig. 3. The semicircle elements observed at high frequency region $\left(10^{-1}-10^{6} \mathrm{~Hz}\right)$ corresponds to the charge transfer limiting process and charge transfer resistance $\left(R_{c t}\right)$.

\subsection{Electrocatalytic voltammetric behavior of ADB}

The electrocatalytic behavior of the designed electrochemical sensors towards the voltammetric determination of $4.5 \times 10^{-7} \mathrm{M}$ Amlodipine in $0.05 \mathrm{M} \mathrm{BR}$ buffer $(\mathrm{pH}$ $10.5 \pm 0.01$ ) at bare and modified CPEs were observed by using $C V$ and adsorptive square wave voltammetry (AdSWV). Cyclic voltammograms of ADB exhibited a single well defined, irreversible, anodic peak in the potential range from $0.0 \mathrm{mV}$ to $+8.0 \times 10^{2} \mathrm{mV}$. The anodic peak observed at $5.2 \times 10^{2} \mathrm{mV}$ is attributed to the oxidation of Amlodipine moiety which was not accompanied by any cathodic peak on reversing the direction of scan, indicating the irreversible nature of reduction process. Figure $4 \mathrm{~A}$ and $B$ compares the electrocatalytic property of bare and modified CPEs towards the determination of $4.5 \times 10^{-7} \mathrm{M}$ ADB.

\subsection{Optimization of conditions}

AdSWV was employed to optimize parameters that affect the sensitivity and propose an accurate and precise determination of $A D B$ in pharmaceutical and biological samples. A variety of buffers with varying strengths were used in determining amlodipine in test solutions. The best results in terms of peak current and voltammogram 

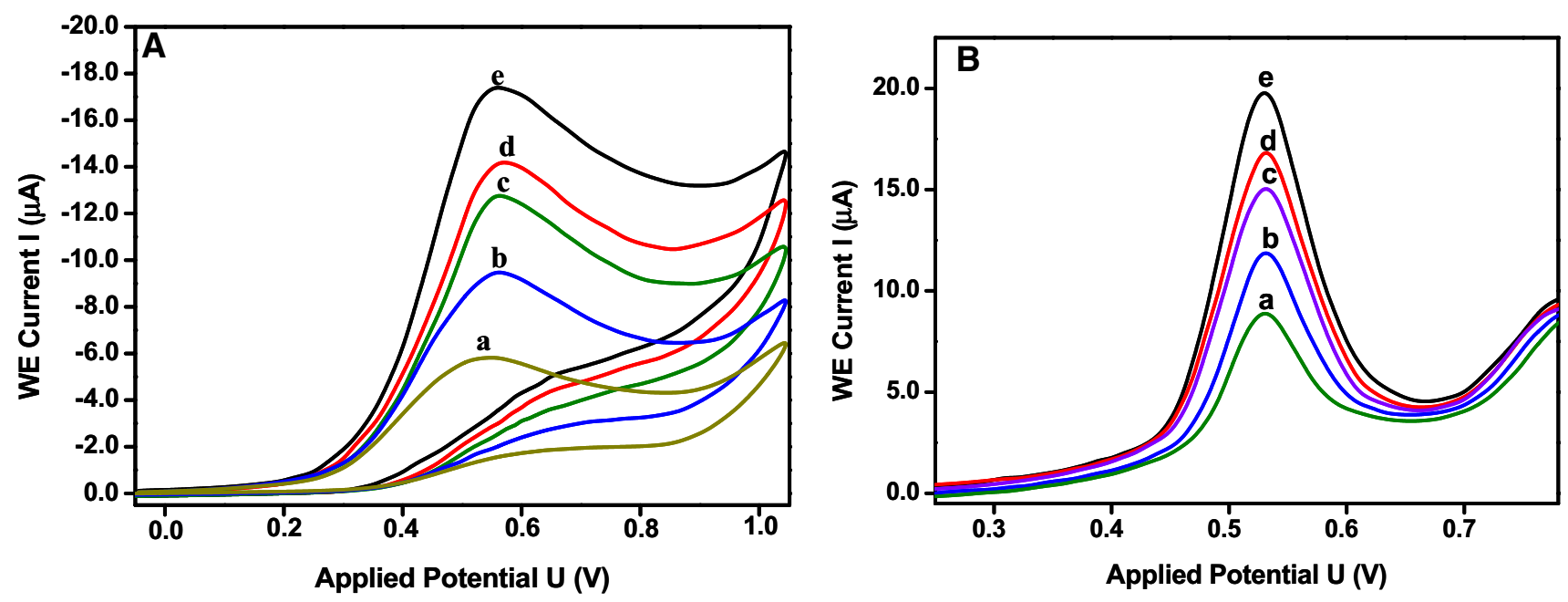

Fig. 4 A Cyclic and B adsorptive square wave voltammograms of $4.5 \times 10^{-7} \mathrm{M}$ amlodipine in $0.05 \mathrm{M}$ BR buffer (pH 10.5) at (a) bare $\mathrm{CPE}$, (b) fMWCNT-CPE, (c) fMWCNT/Cu NP-CPE (d) Ag NP/fMWCNT-CPE and (e) Ag NP/fMWCNT/Cu NP-CPE

shape were obtained with $0.05 \mathrm{M} \mathrm{BR}$ buffer of $\mathrm{pH} 10.5$. A linear plot was observed with a slope of $56.2 \mathrm{mVpH}^{-1}$ when solution $\mathrm{pH}$ was plotted against peak potential. The slope value is close to Nernst's value of $59 \mathrm{mV} \mathrm{pH}^{-1}$ defining that equal electrons and protons are participating in electrode process.

The stripping peak currents was further increased by varying the deposition potential and time from $-5.0 \times 10^{2} \mathrm{mV}$ to $+5.0 \times 10^{2} \mathrm{mV}$ and $0-150 \mathrm{~s}$ respectively. Best peak current was observed when setting a deposition potential of $-5.0 \times 10^{2} \mathrm{mV}$ for $120 \mathrm{~s}$ of accumulation time. Further the instrumental parameters like square wave frequency, step potential of staircase waveform and pulse amplitude were optimized for better peak resolutions. An increase in peak current was observed with increasing frequency however peak crest broadened at higher frequencies. Hence, for sharper peak $40 \mathrm{~Hz}$ frequency was found optimum. The increased step potential and pulse amplitudes tend to increase both peak current and background current. Thus to have better peak current and sharper peak, $10 \mathrm{mV}$ step potential and $20 \mathrm{mV}$ pulse amplitude was optimized resulting in enhanced sensitivity.

\subsection{Kinetic parameters of electrocatalytic oxidation}

\subsubsection{Cyclic voltammetric study}

The cyclic voltammograms of $4.5 \times 10^{-7} \mathrm{M}$ amlodipine in scan range from $10-200 \mathrm{mVs}^{-1}$ were recorded in $0.05 \mathrm{M}$ BR buffer $(\mathrm{pH}=10.5)$ at Ag NP/fMWCNT/Cu NP-CPE and was employed for the determination of various electrokinetic parameters. The relation between the peak current and peak potential with scan rate illustrates whether the electrode process is diffusion or adsorption controlled. The peak current increases gradually with increasing scan rate, while the peak potential shifted anodically indicating the oxidation of amlodipine is an irreversible process (Fig. 5). The plot of $\log I_{p} v s \log v$, (Fig. 5 inset) exhibited a linear relationship expressed by following equation:

$\log I_{p}(\mu A)=0.942 \log v+14.439 R^{2}=0.997$

The value of slope, 0.942 is near to theoretical value of 1.0 for a typical surface adsorptive species. This finding was

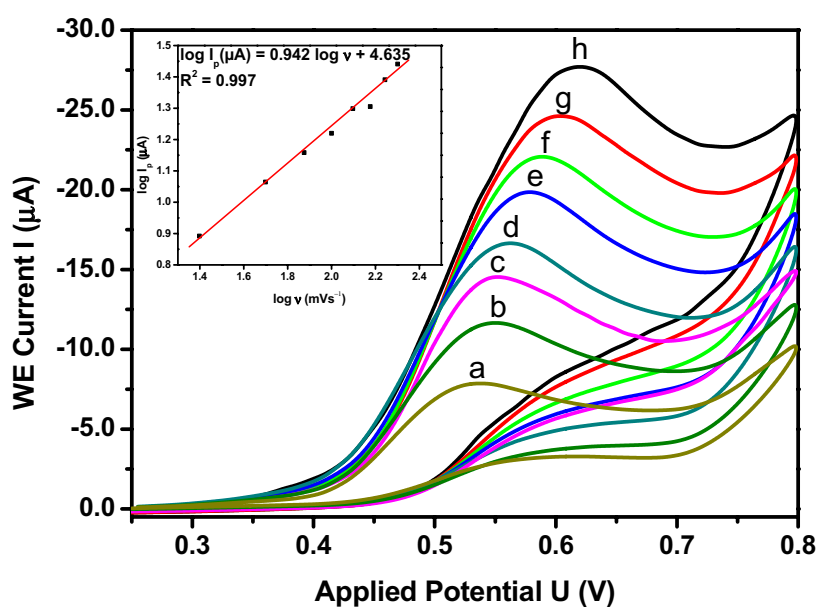

Fig. 5 Cyclic voltammograms of $4.5 \times 10^{-7} \mathrm{M}$ amlodipine in $\mathrm{BR}$ buffer ( $\mathrm{pH} 10.5)$ at Ag NP/fMWCNT/Cu NP-CPE with a scan rate of (a) $25 \mathrm{mVs}^{-1}$, (b) $50 \mathrm{mVs}^{-1}$, (c) $75 \mathrm{mVs}^{-1}$, (d) $100 \mathrm{mVs}^{-1}$, (e) 125 $\mathrm{mVs}^{-1}$, (f) $150 \mathrm{mVs}^{-1}$, (g) $175 \mathrm{mVs}^{-1}$ and (h) $200 \mathrm{mVs}^{-1}$. Inset is plot of logarithm of peak current $v s$. logarithm of scan rate 
well supported by obtaining linear Randles-Sevick plot $\left(I_{p}\right.$ vs $v$ ). For an irreversible electrode process, $n$ (number of electrons transferred), a (electron transfer coefficient), $\mathrm{E}^{0}$ (formal redox potential) and $\mathrm{k}^{0}$ (standard heterogeneous rate constant of the reaction) can be calculated from Laviron's equation [32].

$E_{p}=E^{0}+\left(\frac{2.303 R T}{\alpha n F}\right) \log \frac{R T K^{0}}{\alpha n F}+\left(\frac{2.303 R T}{\alpha n F}\right) \log v$

$W_{1 / 2}=\frac{2.44 R T}{\alpha n F}=\frac{0.0626}{\alpha n}(298 K)$

where, $\mathrm{W}_{1 / 2}$ is the half width of peak, $\mathrm{v}$ is the scan rate and $\mathrm{R}, \mathrm{T}$ and $\mathrm{F}$ are molar gas constant, temperature and Faraday's constant respectively. The value of an can be evaluated from the slope of $E_{p} v s \log v$, the slope was found to be 0.083 and by substituting the values of $R$ and $F$ and taking $\mathrm{T}=298 \mathrm{~K}$, an was calculated to be 0.526 . According to Bard and Faulkner [31], a can be given as:

$\alpha=\frac{47.7}{E_{p}-E_{p / 2}} \quad \mathrm{mV}$ at $298 \mathrm{~K}$

where, $E_{p}$ is peak potential and $E_{p / 2}$ is the half peak potential where current is half of the peak value. Thus, a was calculated to be 0.254 and from this number of electron transferred ( $\mathrm{n}$ ) in the electro-oxidation of amlodipine was calculated as 2.07 ( 2 electron process).

\subsubsection{Controlled potential coulometric behavior and plausible electrode reaction mechanism}

Cyclic and adsorptive stripping square wave voltammetric studies have shown that amlodipine undergoes electrochemical oxidation in BR buffer at $\mathrm{pH}$ 10.5. The electrode process is irreversible at the modified CPEs and $\mathrm{pH}$ studies confirmed the involvement of equal number of protons and electrons. By using controlled potential coulometry, the number of electrons transferred ( $n$ ) can be estimated from the charge consumed by the electrolysis of desired concentration of amlodipine. For this $25 \mathrm{nM}, 50 \mathrm{nM}$ and $75 \mathrm{nM}$ solution of amlodipine was placed in voltammetric cell and electrolysis was carried out at $+4.0 \times 10^{2} \mathrm{mV}$ against $\mathrm{Ag} / \mathrm{AgCl}$ reference electrode. During the electrolysis, solutions were continuously stirred and purged with nitrogen. Number of electrons ' $n$ ' transferred was calculated using the equation $\mathrm{Q}=\mathrm{nFN}$, were $\mathrm{Q}$ is charge in coulombs, $\mathrm{F}$ is Faraday's constant and $\mathrm{N}$ is number of moles of the substance. Three replicate experiments were performed and the value of ' $n$ ' was found to be 1.93, 2.04 and 1.97, thus indicating that the electrode reaction is a two electron process as shown in Scheme 2.

The saturated adsorption capacities of the electrodes were evaluated from chronocoulometric experiment. Faradic charge due to oxidation $\left(\mathrm{Q}_{\mathrm{ads}}\right)$ of amlodipine is determined from $Q$ vs t ${ }^{1 / 2}$ curves using Anson equation [33]:

$Q=\frac{2 n F A c(D t)^{\frac{1}{2}}}{\pi^{\frac{1}{2}}}+Q_{d l}+Q_{a d s}$

where $Q_{d l}$ is the double-layer charge and $D$ is diffusion coefficient. $Q_{d l}$ is supposed to remain similar in absence and presence of amlodipine. The Q-t curves are obtained by applying potential of $+4.0 \times 10^{2} \mathrm{mV}$ in the absence and presence of $4.5 \times 10^{-7} \mathrm{M}$ amlodipine at electrode surface (Fig. 6). Plot of $Q$ vs $t^{1 / 2}$ were drawn after extracting data from Q-t curves and displayed in Fig. 6 inset. The plots of $Q$ vs $\mathrm{t}^{1 / 2}$ showed parallel and linear relationships in absence and presence of amlodipine and the value of $Q_{a d s}$ is estimated from the intercepts and tabulated in Table 1. The experiment is recorded with all modified and bare CPEs. The surface coverage $\left(\left(\Gamma^{*}\right)\right.$ for all electrodes is estimated using the equation [34]:

$Q_{a d s}=n F A \Gamma^{*}$
Scheme 2 The possible oxidation mechanism of ADB<smiles>CCOCC1=C(COCCN)NC(C)=C(C(=O)OC)C1c1ccccc1Cl</smiles> 


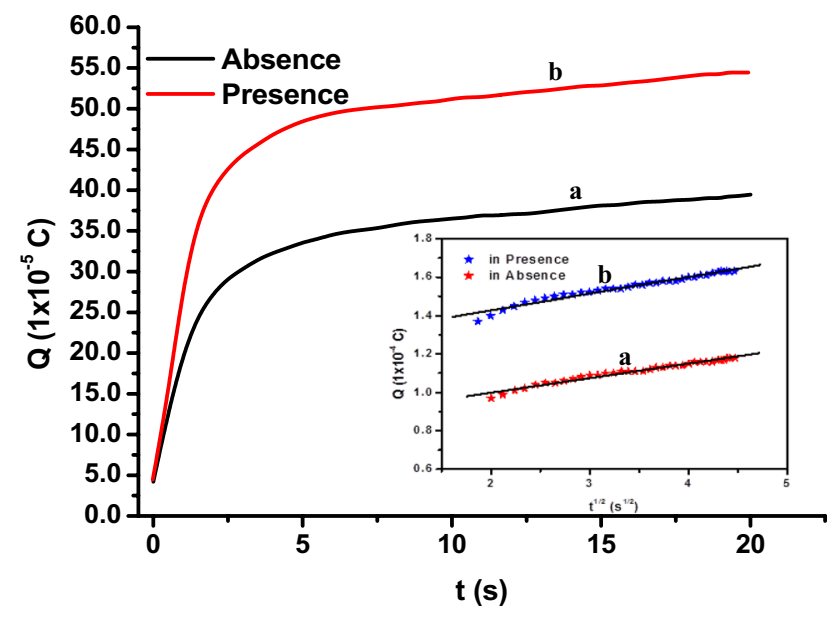

Fig. 6 Chronocoulometric response curves obtained in (a) absence and (b) presence of $4.5 \times 10^{-7} \mathrm{M}$ amlodipine in $\mathrm{BR}$ buffer $(\mathrm{pH}=10.5)$ at the Ag NP/fMWCNT/Cu NP-CPE. Inset: The dependency of charge $\mathrm{Q}\left(10^{-5}\right) v s . \mathrm{t}^{1 / 2}$ data derived from chronocoulometric curves (a) absence and (b) presence of $4.5 \times 10^{-7} \mathrm{M}$ amlodipine

Table 1 Surface coverage $\left(\Gamma^{*}\right)$ and charge due to adsorption $\left(Q_{a d s}\right)$ of electrochemical reaction at electrode surface:

\begin{tabular}{lll}
\hline Electrode & $\mathrm{Q}_{\text {ads }}\left(1 \times 10^{-4} \mathrm{C}\right)$ & $\begin{array}{l}\Gamma^{*} \\
\left(10^{-10} \mathrm{~mol} \mathrm{~cm}^{-2}\right)\end{array}$ \\
\hline b-CPE & 0.0142 & 1.42 \\
fMWCNT-CPE & 0.204 & 3.88 \\
fMWCNT/Cu NP-CPE & 0.702 & 6.98 \\
Ag NP/fMWCNT-CPE & 1.110 & 9.05 \\
AgNP/fMWCNT/Cu NP-CPE & 2.306 & 12.33 \\
\hline
\end{tabular}

\subsubsection{Impedance study}

Electrochemical impedance spectroscopy (EIS) is an excellent technique to elucidate properties like charge transfer resistance $\left(R_{c t}\right)$, apparent electron transfer rate constant $\left(k_{\text {app }}\right)$, double layer capacitance and electro-catalytic oxidation or reduction process at the electrode-analyte interface [16]. The electrode having lower $R_{c t}$ value and higher $k_{a p p}$ is more favorable for redox reactions. EIS study of $4.5 \times 10^{-7} \mathrm{M}$ amlodipine at the surface of bare and all modified CPEs was carried out to assess their $\mathrm{R}_{\mathrm{ct}}$ and $\mathrm{k}_{\mathrm{app}}$. Figure 7 represents the Nyquist plot of $4.5 \times 10^{-7} \mathrm{M}$ amlodipine on bare and modified CPEs. The lower diameter of semi-circle domains obtained in the Nyquist plots upon modification results in decreased $R_{\mathrm{ct}}$ value, thus providing faster electron transfer for oxidation of amlodipine at the electrode surface. The $R_{c t}$ value obtained for Ag NP/fMWCNT/Cu NP-CPE is much smaller than other designed electrodes. The values obtained are $63 \Omega, 172 \Omega, 235 \Omega, 412 \Omega$ and $496 \Omega$ for Ag NP/fMWCNT/ Cu NP-CPE, Ag NP/fMWCNT-CPE, fMWCNT/CU NP-CPE,

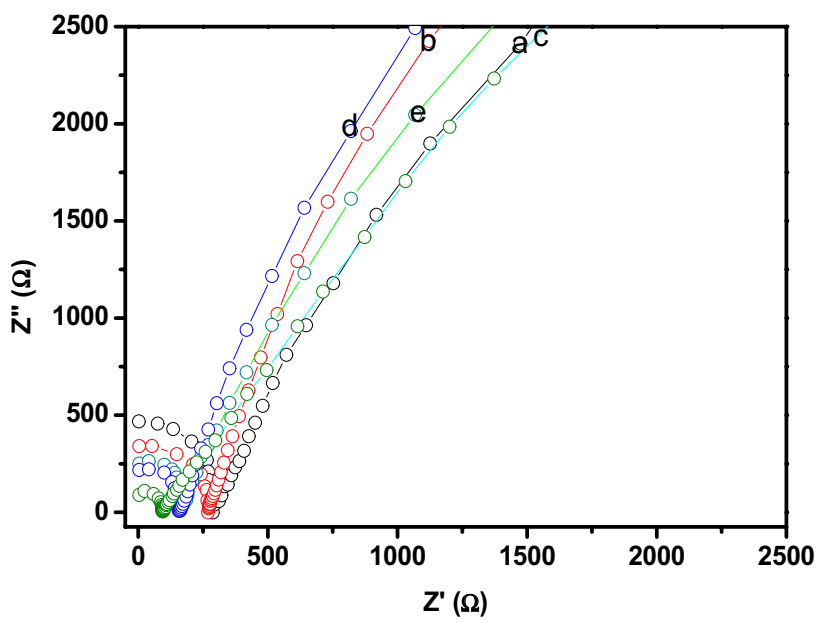

Fig. 7 Nyquist plot observed in presence of $4.5 \times 10^{-7} \mathrm{M}$ amlodipine at (a) b-CPE (b) fMWCNT-CPE (c) fMWCNT/Cu NP-CPE (d) Ag NP/ fMWCNT-CPE (e) Ag NP/fMWCNT/Cu NP-CPE

Table 2 Charge transfer resistance $\left(R_{c t}\right)$ and apparent electron transfer rate constant $\left(\mathrm{k}_{\mathrm{app}}\right)$ of bare and modified electrodes in $4.5 \times 10^{-7} \mathrm{M}$ amlodipine

\begin{tabular}{lll}
\hline Electrode & $\mathrm{R}_{\mathrm{ct}}(\Omega)$ & $\begin{array}{l}\mathrm{k}_{\mathrm{app}}\left(\times 10^{-}\right. \\
\left.5 \mathrm{~cm} \mathrm{~s}^{-1}\right)\end{array}$ \\
\hline $\mathrm{b}-\mathrm{CPE}$ & 497 & 1.19 \\
fMWCNT-CPE & 326 & 1.44 \\
fMWCNT/Cu NP-CPE & 205 & 2.52 \\
Ag NP/fMWCNT-CPE & 174 & 3.44 \\
Ag NP/fMWCNT/Cu NP-CPE & 83 & 9.39 \\
\hline
\end{tabular}

fMWCNT-CPE and CPE respectively. The apparent electron transfer rate constant $\left(\mathrm{k}_{\mathrm{app}}\right)$ is calculated using equation [35]:

$k_{\text {app }}=\frac{R T}{F^{2} R_{c t} C}$

where $R_{c t}$ is the resistance to charge transfer, $C$ is the concentration of $A D B$ and other terms have their usual meaning. The calculated values of $k_{\text {app }}$ for different electrodes are listed in Table 2. The results confirm faster electrons transfer at Ag NP/fMWCNT/Cu NP-CPE relative to the other electrodes which is due to combinatorial excellent electric properties of silver and copper.

\subsection{Analytical applications}

\subsubsection{Linearity and calibration graph}

The analytical performance of the proposed method as an analytical tool was validated by measuring peak current $\left(I_{p}\right)$ as a function of concentration of amlodipine by AdSWV 
at Ag NP/fMWCNT/Cu NP-CPE. The calibration plot of $\mathrm{I}_{\mathrm{p}}$ versus concentration gives best linear correlation in the concentration range of $2.0 \times 10^{-8} \mathrm{M}$ to $6.3 \times 10^{-6} \mathrm{M}$ using AdSWV in BR buffer ( $\mathrm{pH}$ 10.5) at Ag NP/fMWCNT/Cu NPCPE. The limit of detection (LOD) and limit of quantification $(\mathrm{LOQ})$ were calculated using $\angle O D=\frac{3 \mathrm{~s}}{\mathrm{~m}}$ and $L O Q=\frac{10 \mathrm{~s}}{\mathrm{~m}}$ equations [3]. Where $s$ is the standard deviation of the intercept $(n=5), m$ is the slope of the regression line. The calculated LOD was found to be $5.16 \times 10^{-10} \mathrm{M}$ with LOQ was amounted to be $1.72 \times 10^{-9} \mathrm{M}$. The \%RSD for five measurements at each concentration $(n=5)$ were ranged from $1.21 \%$ to $2.17 \%$. Table 3 compares the response characteristics of proposed method with some other reported analytical methods for the determination of ADB.

\subsubsection{Accuracy and precision}

The accuracy and precision of the proposed method at the fabricated Ag NP/fMWCNT Cu NP-CPE was validated by spiking with known amounts (pre-analyzed) of test solution under optimized condition. The accuracy (\% bias) was expressed in terms of mean relative error. The \% bias values varies between $-0.4 \%$ to $0.05 \%$ which are highly acceptable and show better accuracy of the method. The precision of the proposed method was determined by analyzing amlodipine in pre-analyzed sample solutions for four successive days with five replications. The \% recovery and \% RSD (relative standard deviation) based on the average of five replicates were determined. The results confirm better accuracy and precision with low mean variation coefficient of $0.119 \%$ and mean \% recoveries of 100.01 for AdSWV.

\subsubsection{Stability and reproducibility}

To study the fabrication reproducibility of $\mathrm{Ag}$ NP/fMWCNT/Cu NP-CPE, five electrodes were designed via same procedure and applied for analyzing $4.5 \times 10^{-7} \mathrm{M}$ amlodipine under optimized parameters with AdSWV. The average \% RSD of peak current and peak potential for average of 5 replicated analyses on each fabricated electrode are $1.027 \%$ and $0.185 \%$ respectively. The repeatability of developed method over single modified electrode was estimated by analyzing 10 replicate determination of $4.5 \times 10^{-7} \mathrm{M}$ test solution using AdSWV. The mean concentration was found to be $4.997 \times 10^{-7} \mathrm{M}$ with a standard deviation of 0.0036 and \% RSD of 1.014. The results revealed that modified electrode has high reproducibility and repeatability in both fabrication procedure and signal determination.

For long term stability of Ag NP/fMWCNT/Cu NP$\mathrm{CPE}$ the electrode was stored at room temperature for 10 to 25 days. The voltammograms were recorded for $4.5 \times 10^{-7} \mathrm{M}$ amlodipine and compared with the voltammogram recorded with freshly prepared electrode for same concentration. The result (for $n=5$ ) reveal that peak current deflected a tad ( $\pm 2.19 \%$ of initial current) with \% RSD of 1.027 which indicates the good stability of electrode. These results established good stability and capability of modified electrode to perform repeated measurements (Fig. 8).

\subsubsection{Analysis of real samples}

The feasibility of Ag NP/fMWCNT/Cu NP-CPE and of the developed procedure was verified by analyzing amlodipine in real samples (Human blood plasma, serum and urine and pharmaceutical formulations) under optimized condition. Initially, no voltammetric response corresponding to amlodipine was observed indicating that real sample was either absolutely free of amlodipine or may have concentration below detection limit. The quantitative determination of spiked amlodipine was carried out by standard addition method and calibration curve were drawn to obtain the recovery result. The biological samples spiked with three different known concentrations of amlodipine and voltammograms were recorded using AdSWV. The results are summarized in Table 4 . The \% recoveries indicated the sensitivity of modified electrode and applicability of the proposed method in real samples.
Table 3 Comparison of various reported analytical methods for the determination of amlodipine:

\begin{tabular}{llll}
\hline Analytical method & Linear range & LOD & References \\
\hline $\begin{array}{l}\text { Adsorptive square-wave anodic stripping } \\
\text { voltammetry }\end{array}$ & $4.0 \times 10^{-8} \mathrm{M}$ to $2.0 \times 10^{-6} \mathrm{M}$ & $1.4 \times 10^{-8} \mathrm{M}$ & {$[19]$} \\
Differential pulse stripping voltammetry & $1.0 \times 10^{-8} \mathrm{M}$ to $3.0 \times 10^{-7} \mathrm{M}$ & $5.0 \times 10^{-9} \mathrm{M}$ & {$[21]$} \\
Square wave voltammetry & $5.0 \times 10^{-9} \mathrm{M}$ to $1.0 \times 10^{-6} \mathrm{M}$ & $1.0 \times 10^{-9} \mathrm{M}$ & {$[36]$} \\
Spectrofluorometric method & $2.0 \times 10^{-7} \mathrm{M}$ to $3.6 \times 10^{-6} \mathrm{M}$ & $2.5 \times 10^{-8} \mathrm{M}$ & {$[37]$} \\
Adsorptive square wave voltammetry & $2.0 \times 10^{-8} \mathrm{M}$ to $6.3 \times 10^{-6}$ & $5.16 \times 10^{-10} \mathrm{M}$ & Present work \\
\hline
\end{tabular}




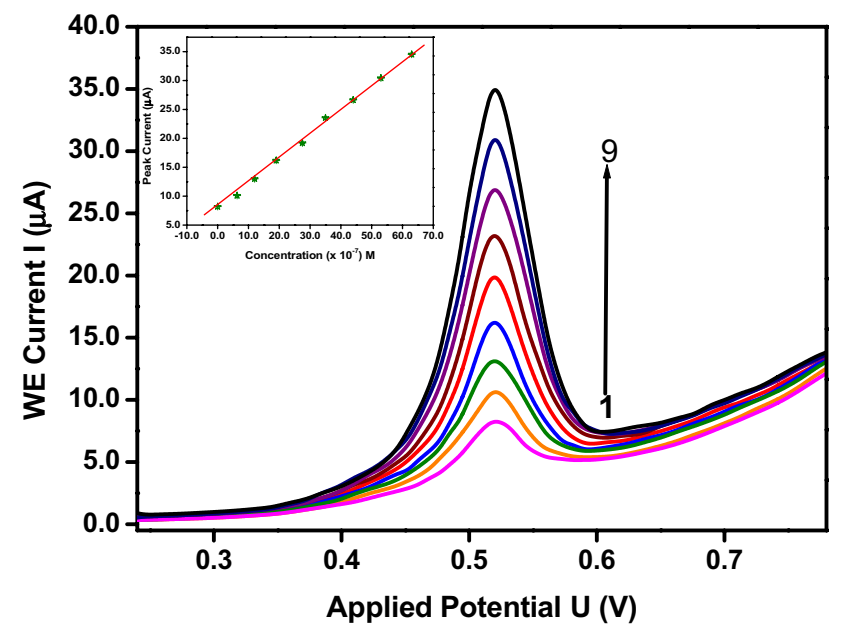

Fig. 8 Adsorptive square wave voltammograms of $(1 \rightarrow 9)$ $0.002 \mu \mathrm{M}, 0.630 \mu \mathrm{M}, 1.20 \mu \mathrm{M}, 1.90 \mu \mathrm{M}, 2.75 \mu \mathrm{M}, 3.50 \mu \mathrm{M}, 4.40 \mu \mathrm{M}$, $5.30 \mu \mathrm{M}$ and $6.30 \mu \mathrm{M}$ amlodipine in BR buffer $(\mathrm{pH}=10.5)$ at $\mathrm{Ag}$ NP/fMWCNT/Cu NP-CPE surface. Inset: Linear dependence of peak current with concentration of amlodipine

Table 4 Determination of amlodipine in real samples using AdSWV

\begin{tabular}{lllcl}
\hline Sample & Spiked amount & Found & Recovery \% & RSD \% \\
\hline Amlodac & $5 \mathrm{mg}$ (label claim) & 4.989 & 99.78 & 1.12 \\
Amlopin & $5 \mathrm{mg}$ (label claim) & 4.998 & 99.96 & 0.19 \\
Serum & $0.8 \mu \mathrm{M}$ & $0.801 \mu \mathrm{M}$ & 100.12 & 1.13 \\
& $0.6 \mu \mathrm{M}$ & $0.599 \mu \mathrm{M}$ & 99.83 & 2.07 \\
& $0.4 \mu \mathrm{M}$ & $0.403 \mu \mathrm{M}$ & 100.75 & 0.94 \\
Plasma & $0.8 \mu \mathrm{M}$ & $0.798 \mu \mathrm{M}$ & 99.75 & 1.26 \\
& $0.6 \mu \mathrm{M}$ & $0.594 \mu \mathrm{M}$ & 99.00 & 1.84 \\
& $0.4 \mu \mathrm{M}$ & $0.396 \mu \mathrm{M}$ & 99.00 & 1.05 \\
Urine & $0.8 \mu \mathrm{M}$ & $0.802 \mu \mathrm{M}$ & 100.25 & 0.84 \\
& $0.6 \mu \mathrm{M}$ & $0.601 \mu \mathrm{M}$ & 100.16 & 0.91 \\
& $0.4 \mu \mathrm{M}$ & $0.398 \mu \mathrm{M}$ & 99.50 & 1.17 \\
\hline
\end{tabular}

\section{Discussion}

Our results confirm that the successful development of highly sensitive, selective and stable Ag NP/fMWCNT/ $\mathrm{Cu}$ NP-CPE and its efficient response towards the calcium channel blocker drug amlodipine besylate in blood plasma and various pharmaceutical preparations with a low detection limit of $5.16 \times 10^{-10} \mathrm{M}$. The observed $\triangle \mathrm{E}_{\mathrm{p}}$ values for $\mathrm{fMWCNT}$-CPE, fMWCNT/CU NP-CPE, Ag NP/fMWCNT-CPE and Ag NP/fMWCNT/CU NP-CPE are $2.41 \times 10^{2} \mathrm{mV}, 1.95 \times 10^{2} \mathrm{mV}, 1.44 \times 10^{2} \mathrm{mV}$ and $87 \mathrm{mV}$ respectively, confirmed the improvisation in the performance towards the detection of ADB drug which might be attributed to the successful deposition of $\mathrm{Ag}$ NPs and Cu NPs on the FMWCNT-CPE.. The EIS results implies that the charge transfer resistance $\left(R_{c t}\right)$ at $A g$ $\mathrm{NP} / \mathrm{fMWCNT} / \mathrm{Cu}$ NP-CPE $\left(\mathrm{R}_{\mathrm{ct}}=67.4 \Omega\right)$ is lower than that of AgNP/fMWCNT-CPE $\left(R_{c t}=147 \Omega\right)$, fMWCNT/CU NPCPE $\left(R_{c t}=185 \Omega\right)$, fMWCNT-CPE $\left(R_{c t}=324 \Omega\right)$ and b-CPE $\left(R_{c t}=415 \Omega\right)$. These observations indicate excellent combined electrocatalytic property of Ag NPs, Cu NPs and $f M W C N T$ in addition to properties like high aspect ratio, good conductivity, easier and faster charge transfer at electrode surface. The increased electron transfer rate, high electroactive surface area and admirable electrode conductivity of nanoparticles was evident by observing increased peak current intensities at the modified electrodes. The Ag NP film over fMWCNT/Cu NP hybrid exerts a significant catalytic activity in the oxidation of ADB (Fig. 4A, B).

\section{Conclusion}

AgNPs were successfully deposited on $\mathrm{fMWCNT/Cu} \mathrm{NP-}$ $\mathrm{CPE}$ via electrocatalytic process. The designed electrode (AgNPs/fMWCNT/Cu NP-CPE) exhibits excellent structural features like large electroactive surface area, faster electron transfer rates, predominant electrocatalytic activity, acceptable reproducibility (both in fabrication procedure and signal determination) and long-term stability. The sensor evinced high efficacy towards the determination of a hyper-tensive drug ADB. Furthermore, the sensor demonstrated a linear response for $A D B$ in the range $2.0 \times 10^{-8} \mathrm{M}$ to $6.3 \times 10^{-6} \mathrm{M}$ and with a low detection limit of $5.16 \times 10^{-10} \mathrm{M}$. In addition, this study can open the way for designing cheap and highly efficient sensors for the analysis of forensic drugs, quality control processes, heavy metal analysis, water quality analysis as well as future potential applications in this filed.

Acknowledgements Authors are highly thankful to the Department of Chemistry and Sophisticated Instrumentation Laboratory (SIL) of Dr. Hari Singh Gour University, Sagar, India for providing the necessary facilities to complete the work.

Author contributions First and second author has contributed $50 \%$ and rest of the contribution from other authors.

Data availability All data is given in the manuscript.

\section{Compliance with ethical standards}

Competing interests The authors declare that they have no competing interests. 


\section{References}

1. Kulkarni DR, Malode SJ, Prabhu KK, Ayachit NH, Kulkarni RM, Shetti NP (2020) Development of a novel nanosensor using Ca-doped ZnO for antihistamine drug. Mater Chem Phys 246:122791

2. Dakshayinia BS, Reddy KR, Mishrac A, Shetti NP, Maloded SJ, Basuc S, Naveene S, Raghue AV (2019) Role of conducting polymer and metal oxide based hybrids for application in ampereometric sensors and biosensors. Microchem J 147:7-24

3. Shetti NP, Malode SJ, Bukkitgar SD, Bagihalli GB, Kulkarni RM, Pujari SB, Reddy KR (2019) Electro-oxidation and determination of nimesulide at nanosilica modified sensor. Mater Sci Energy Technol 2:396-400

4. Shetti NP, Shanbhaga MM, Malode SJ, Srivastava RK, Reddy KR (2020) Amberlite XAD-4 modified electrodes for highly sensitive electrochemical determination of nimesulide in human urine. Microchem J 153:104389

5. Bukkitgar SD, Shetti NP, Malladi RS, Reddy KR, Kalanur SS, Aminabhavi TM (2019) Novel ruthenium doped TiO2/reduced graphene oxide hybrid as highly selective sensor for the determination of ambroxol. J Mol Liq 300:112368

6. Shetti NP, Malode SJ, Nayak DS, Bukkitgar SD, Bagihalli GB, Kulkarni RM, Reddy KR (2020) Novel nanoclay-based electrochemical sensor for highly efficient electrochemical sensing nimesulide. J Phys Chem Solids 137:109210

7. Honakeri NC, Malode SJ, Kulkarni RM, Shetti NP (2020) Electrochemical behavior of diclofenac sodium at coreshell nanostructure modified electrode and its analysis in human urine and pharmaceutical samples. Sensors Int 1:100002

8. Bhakta AK, Kumari S, Hussain S, Martis P, Mascarenhas RJ, Delhalle J, Mekhalif Z (2019) Synthesis and characterization of maghemite nanocrystals decorated multi-wall carbon nanotubes for methylene blue dye removal. J Mater Sci 54:200-216

9. Manasa G, Mascarenhas RJ, Satpati AK, Basavaraja BM, Kumar S (2018) An electrochemical Bisphenol F sensor based on $\mathrm{ZnO} / \mathrm{G}$ nano composite and CTAB surface modified carbon paste electrode architecture. Colloids Surf B 170:144-151

10. Veera $Y$, Reddy $M$, Sravani $B$, Maseed H, Łuczak T, Osińska M, Sarma LS, Srikanth VVSS, Madhavi G (2018) Ultrafine Pt-Ni bimetallic nanoparticles anchored on reduced graphene oxide nanocomposites for boosting electrochemical detection of dopamine in biological samples. New J Chem 42:16891-16901

11. Sravani $B$, Raghavendra $P$, Chandrasekhar $Y$, Veera $Y$, Reddy $M$, Sivasubramanian R, Venkateswarlu K, Madhavi G, Subramanyam SL (2020) Immobilization of platinum-cobalt and platinumnickel bimetallic nanoparticles on pomegranate peel extracttreated reduced graphene oxide as electrocatalysts for oxygen reduction reaction. Int J Hydrogen Energ 45:7680-7690

12. Chen A, Chatterjee S (2013) Nanomaterials based electrochemical sensors for biomedical applications. Chem Soc Rev 42:5425-5438

13. Brahman PK, Suresh L, Lokesh V, Nizamuddin S (2016) Fabrication of highly sensitive and selective nanocomposite film based on CuNPs/Fullerene- $\mathrm{C}_{60}$ /MWCNTs: an electrochemical nanosensor for trace recognition of paracetamol. Anal Chim Acta 917:107-116

14. Ren J, Li L, Cui M, Zhai M, Yu C, Ji X (2016) Nitrobenzene electrochemical sensor based on silver nanoparticle supported on poly-melamine functional multi-walled carbon nanotubes. Ionics 22:1937-1947

15. Habibi B, Jahanbakhshi M (2014) Silver nanoparticles/multi walled carbon nanotubes nanocomposite modified electrode: Voltammetric determination of clonazepam. Electrochim Acta 118:10-17
16. Zargar B, Parham H, Hatamie A (2014) Electrochemical investigation and stripping voltammetric determination of captopril at $\mathrm{CuO}$ nanoparticles/multi-wall carbon nanotube nanocomposite electrode in tablet and urine samples. Anal Methods 7:1026-1035

17. Carvalho $M$, Oliveria $C H$, Mendes $G D$, Sucupira $M$, Moraces $M E$, De NG (2002) Amlodipine bioequivalence study: quantifiqation by LC coupled to tandem mass spectrometry. Biopharm Drug Dispos 22:383-390

18. Bhatt J, Singh S, Shah SGB, Kambli S, Ameta SA (2007) Rapid and sensitive LC-MS/MS method for estimation of Amlodipine in human plasma. Biomed Chromatogr 21:169-175

19. Gazy AA (2004) Determination of Amlodipine Besylate by adsorptive square-wave anodic stripping Voltammetry on glassy carbon electrode in tablets and biological fluids. Talanta 62:575-582

20. Sridhar K, Sastry CSP, Reddy MN, Sankar DG, Srinivas KR (1997) Spectrophotometric determination of Amlodipine Besylate in pure forms and Tablets. Anal Lett 30:121-133

21. Sikkander ARM, Vedhi C, Manisankar P (2012) Electrochemical determination of calcium channel blocker drugs using multiwall carbon nanotube-modified glassy carbon electrode. Int J Ind Chem 3:29-36

22. Sikkander ARM, Vedhi C, Manisankar P (2011) Electrochemical stripping studies of Amlodipine using MWCNT modified Glassy carbon electrode. Chem Mater Res 1:1-7

23. Burguete CP, Linares-Solano A, Rodríguez-Reinoso F, Lecea CSM (1989) The effect of oxygen surface groups of the support on platinum dispersion in Pt/carbon catalysts. J Catal 115:98-106

24. Cuentas-Gallegos AK, Martínez-Rosales R, Rincón ME, Hirata GA, Orozco G (2006) Design of hybrid materials based on carbon nanotubes and polyoxometalates. Opt Mater 29:126-133

25. Smith B, Wepasnick K, Schrote KE, Cho HH, Ball WP, Fairbrother $\mathrm{DH}$ (2009) Influence of surface oxides on the colloidal stability of multi-walled carbon nanotubes: a structure-property relationship. Langmuir 25:9767-9776

26. Avilés F, Cauich-Rodríguez JV, Moo-Tah L, May-Pat A, VargasCoronado R (2009) Evaluation of mild acid oxidation treatments for MWCNT functionalization. Carbon 47:2970-2975

27. Haydar S et al (2000) Regularities in the temperature-programmed desorption spectra of $\mathrm{CO} 2$ and $\mathrm{CO}$ from activated carbons. Carbon 38:1297-1308

28. Wilson $\mathrm{H}$ et al (2016) Electrical monitoring of sp3 defect formation in individual carbon nanotubes. J Phy Chem C 120:1971-1976

29. Gao C, Li W, Jin YZ, Kong H (2006) Facile and large-scale synthesis and characterization of carbon nanotube/silver nanocrystal nanohybrids. Nanotechnology 17:2882-2890

30. Habibi B, Jahanbakhshi M (2006) Silver nanoparticles/multi walled carbon nanotubes nanocomposite modified electrode: Voltammetric determination of clonazepam. Electrochim Acta 118:10-17

31. Pandit UJ, Khan I, Wankar S, Raj KK (2015) Limaye SN (2015) Development of an electrochemical method for the determination of bicalutamide at the SWCNT/CPE in pharmaceutical preparations and human biological fluids. Anal Methods 7:10192-10198

32. Qiao W, Wang L, Ye B, Li G, Li J (2015) Electrochemical behavior of palmatine and its sensitive determination based on an electrochemically reduced L-methionine functionalized graphene oxide modified electrode. Analyst 140:7974-7983

33. Anson F (1964) Application of potentiostatic current integration to the study of the adsorption of cobalt (III)-(ethylenedinitrilotetraacetate)) on mercury electrodes. Anal Chem 36:932-934

34. Qiao W, Wang L, Ye B, Li G, Li J (2015) Electrochemical behaviour of palmatine and its sensitive determination based on an 
electrochemically reduced L-methionine functionalized graphene oxide modified electrode. Analyst 140:7974-7983

35. Maringa A, Mugadza T, Antunes E, Nyokong T (2013) Characterization and electrocatalytic behaviour of glassy carbon electrode modified with nickel nanoparticles towards amitrole detection. J Electroanal Chem 700:86-92

36. Goyal RN, Bishnoi S (2010) Voltammetric determination of amlodipine besylate in human urine and pharmaceuticals. Bioelectrochemistry 79:234-240
37. Shaalan RA, Belal TS (2010) Simultaneous Spectrofluorimetric determination of amlodipine besylate and valsartan in their combined tablets. Drug Test Anal 2:489-493

Publisher's Note Springer Nature remains neutral with regard to jurisdictional claims in published maps and institutional affiliations. 